\title{
8
}
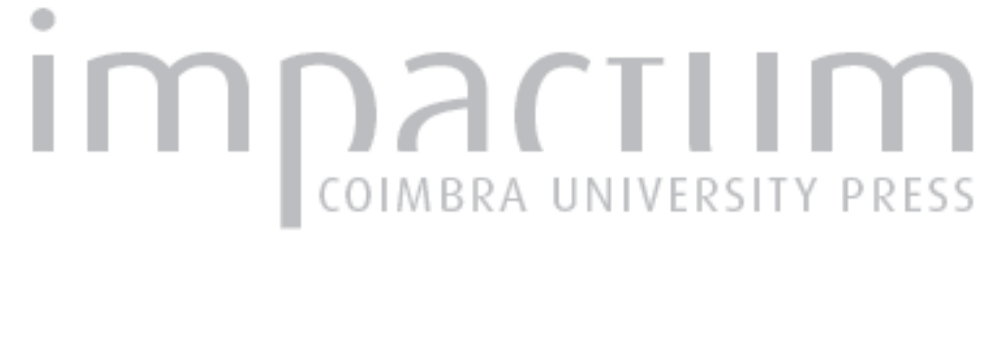

Territórios em mudança e os incêndios na interface urbano-florestal: estudo de caso em Baião
Autor(es):
Fidalgo, Emanuel Sardo

Publicado por:

Faculdade de Letras da Universidade de Coimbra, Departamento de Geografia

URL

persistente:

URl:http://hdl.handle.net/10316.2/30204

DOI:

DOI:http://dx.doi.org/10.14195/0871-1623_31_8

Accessed : $\quad$ 26-Apr-2023 09:39:12

A navegação consulta e descarregamento dos títulos inseridos nas Bibliotecas Digitais UC Digitalis, UC Pombalina e UC Impactum, pressupõem a aceitação plena e sem reservas dos Termos e Condições de Uso destas Bibliotecas Digitais, disponíveis em https://digitalis.uc.pt/pt-pt/termos.

Conforme exposto nos referidos Termos e Condições de Uso, o descarregamento de títulos de acesso restrito requer uma licença válida de autorização devendo o utilizador aceder ao(s) documento(s) a partir de um endereço de IP da instituição detentora da supramencionada licença.

Ao utilizador é apenas permitido o descarregamento para uso pessoal, pelo que o emprego do(s) título(s) descarregado(s) para outro fim, designadamente comercial, carece de autorização do respetivo autor ou editor da obra.

Na medida em que todas as obras da UC Digitalis se encontram protegidas pelo Código do Direito de Autor e Direitos Conexos e demais legislação aplicável, toda a cópia, parcial ou total, deste documento, nos casos em que é legalmente admitida, deverá conter ou fazer-se acompanhar por este aviso.

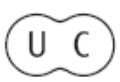




\section{Territórios em mudança e os incêndios na interface urbano-florestal. Estudo de caso em Baião}

\section{Emanuel Sardo Fidalgo}

Mestre em Dinâmicas Sociais, Riscos Naturais e Tecnológicos, pelas Faculdade de Ciências e Tecnologia, Faculdade de Economia e Faculdade de Letras da Universidade de Coimbra.

emanuel.s.fidalgo@gmail.com

\section{Resumo:}

A presença do elemento humano no seu quotidiano, quer em situações de trabalho ou de lazer, acarreta sempre riscos. Portugal, geograficamente integrado na bacia do Mediterrâneo, possui características favoráveis à deflagração e propagação de incêndios florestais, nomeadamente no estio. Apesar de não serem um fenómeno recente, os incêndios florestais na interface urbano florestal (IUF) têm ganho realce por quanto os seus danos são cada vez maiores, resultado do aumento das áreas com tais características. Atualmente, as dinâmicas territoriais, demográficas e sociais verificadas, nomeadamente nas áreas rurais de montanha do noroeste, resultam num cenário que agravou a ocorrência de incêndios na IUF.

Palavras-chave: Interface urbano-florestal. Risco. Vulnerabilidade. Resiliência.

\section{Résumé:}

Changement dans les territoires et les incendies dans le interface habitat-forêt. Étude de cas à Baião

Il n'y a aucune activité humaine, que ce soit pour affaires ou plaisir qui n’a pas de risques. Portugal, géographiquement intégré dans le bassin méditerranéen, présente des caractéristiques favorables à l'apparition et la propagation des feux de forêts particulièrement en été. Bien que n'étant pas un phénomène récent, les feux de forêt dans l'interface habitat-forêt (IHF) ont acquis une notoriété que ses pertes sont en augmentation en raison de l'expansion des zones avec de telles caractéristiques. Actuellement, les dynamiques territoriales, les changements démographiques et sociaux qui se produisent, principalement dans la zone rurale de montagne du nord-ouest, se traduisent par un scénario favorable à la survenance d'incendies dans l'IHF.

Mots-clés: Interface habitat-forêt. Risque. Vulnérabilité. Résilience.

\section{Abstract:}

Territories in change and the fires in wildland urban interface. Case study in Baião

The presence of the human element, in work situations or leisure, always carries risks. Portugal, geographically integrated in the Mediterranean basin, has favourable characteristics to the outbreak of forest fires especially in the summer. Although not a recent phenomenon, the forest fires in the Wildland Urban Interface (WUI) have gained notoriety because its damages are increasing as a result of expansion of areas with such characteristics. Presently, there are in the rural mountain regions of northwestern Portugal some territorial dynamics, demographic and social changes, result in a scenario that aggravated the occurrence of wildfires in the WUI.

Keywords: Wildland-urban interface. Risk. Vulnerability. Resilience. 


\section{Introdução}

Em Portugal, nas regiões de montanha do Norte e Centro, mas sobretudo no noroeste português, as características do povoamento traduzem-se numa dispersão de habitações e outras infra-estruturas pelo território. Assim, uma larga extensão do território assume características de Interface Urbano Florestal (IUF), que é agravada pelas tendências demográficas e sociais, nomeadamente o despovoamento e/ou a procura crescente de segundas residências em áreas rurais, como sucede em Baião, o território do estudo de caso.

Localizado no Norte de Portugal, integrando o distrito do Porto e a NUT III Tâmega, Baião tem uma área aproximada de $175 \mathrm{~km}^{2}$, distribuída por 20 freguesias e uma população residente de 20522 habitantes, segundo os Censos 2011 (Figura 1).

As suas características biofísicas são sensivelmente homogéneas no território, contudo, a altitude é o elemento que condiciona o tipo de ocupação e usos do solo que aí se encontram. Acima de 600/700 metros de altitude o povoamento humano é pouco expressivo, com o coberto vegetal constituído essencialmente por carvalhais espontâneos e matos (giestas, tojos e carqueja). Neste contexto, a generalidade dos incêndios que aqui ocorrem não assumem as características de que se revestem os incêndios florestais na IUF, pois é nos vales e áreas deprimidas desde os 80/100 metros, ao longo do rio Douro, até meia vertente, das serras do Marão, Aboboreira e Castelo e montes adjacentes, que se encontra a ecúmena. É neste contexto que, intricado com os campos agrícolas, surge e se desenvolve o povoamento, predominantemente disperso, salvo poucas exceções, criando áreas significativas de interface urbano-florestal. Este é o cenário propício à ocorrência de incêndios florestais, que cada vez mais se têm aproximado de aglomerados populacionais.

Consequência do êxodo rural é o despovoamento que reforça a perda de importância do sector primário e de atividade tais como a agricultura, a pastorícia ou a silvicultura. Assim, todo um leque de práticas que mantinham a paisagem rural com as áreas silvo-pastoris e agrícolas bem definidas, perdem-se, conduzindo à crescente promiscuidade entre elas. É pois inevitável que os campos dêem lugar a matagais, quebrando a descontinuidade entre a floresta e as habitações, surgindo uma maior fragmentação entre as áreas urbanizadas e as agro-florestais. Muito embora o sector secundário seja o que mais população emprega neste território, ainda assim, é marcadamente rural, não tendo ainda perdido a sua matriz agrícola.

Atualmente, a manutenção de práticas agrícolas e pastoris, mesmo a tempo parcial, são as atividades que mais contribuem para a criação de descontinuida-
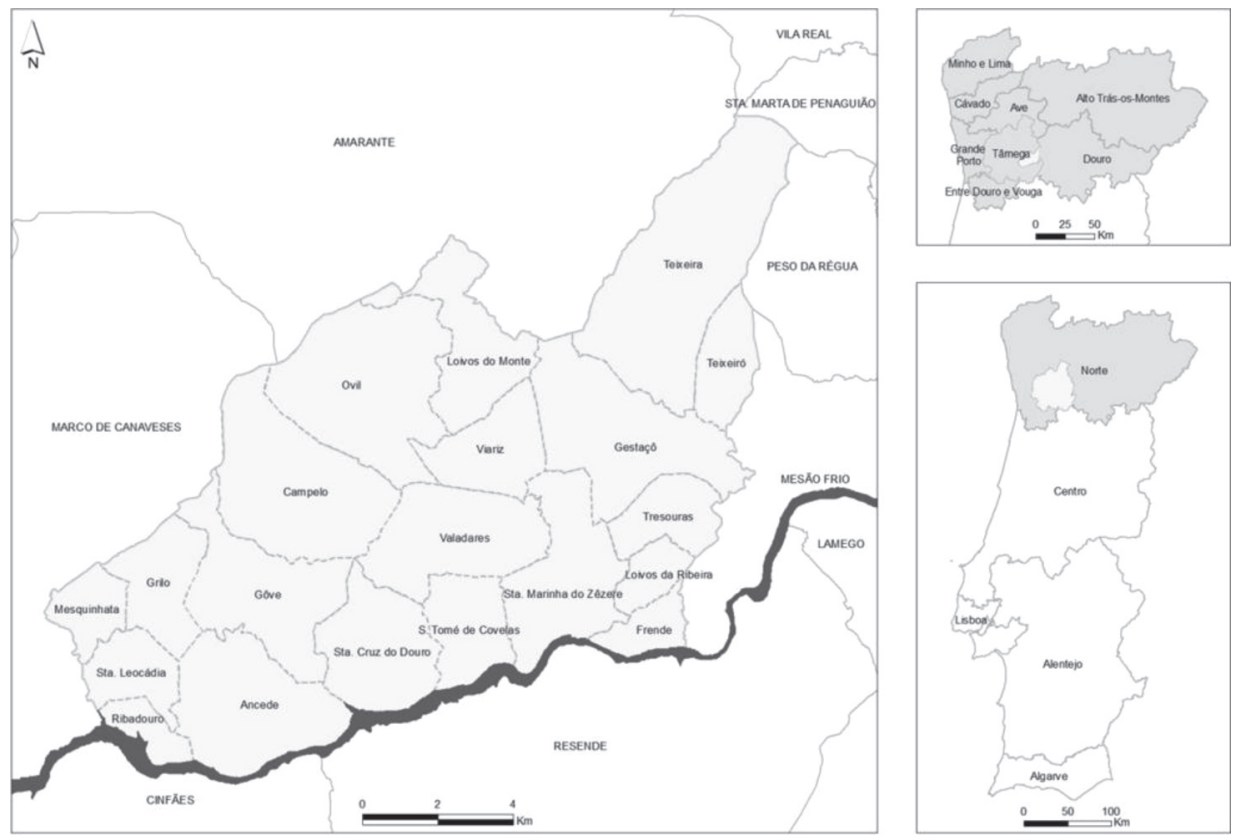

Figura 1

Localização do concelho de Baião.

Fonte: Carta Administrativa Oficial de Portugal, IGP. Elaboração própria. 
des entre a floresta e as povoações, assumindo, deste modo, uma crescente importância na prevenção de incêndios florestais na IUF.

\section{A problemática dos incêndios na interface urbano- florestal}

\subsection{Dinâmicas territoriais}

No passado, a floresta em Portugal caracterizavase pela diversidade de espécies adaptadas às características do clima mediterrâneo, sobretudo a secura na época estival. Apesar disso, ao longo dos séculos, em virtude da sua sobre-exploração, do arroteamento para a agricultura e expansão de áreas urbanas e dos incêndios, esta floresta tem vindo a degradar-se e a sua área a reduzir-se significativamente.

A partir de meados do século passado, os eucaliptais, particularmente o Eucalyptus globulus tem vindo, gradualmente, a substituir os pinhais. Segundo PAIVA (2010: 2) "os eucaliptos interessam mais às celuloses por serem árvores de crescimento mais rápido do que os pinheiros. Nas últimas décadas incrementaram-se tão desenfreadamente as plantações de eucaliptos que se criou em Portugal a maior área de eucaliptal contínuo da Europa."

Com a adesão à União Europeia, a Política Agrícola Comum em 1992 e reforçando a tese de que "Portugal é um país eminentemente florestal", dando resposta aos elevados excedentes agrícolas da UE, surgem medidas como a SET ASIDE em que áreas anteriormente agrícolas dariam lugar a floresta. Esta medida contribuiu para acelerar o êxodo rural, da população com ocupação agrícola, já iniciado na década de sessenta do século XX.

O Regulamento CEE $n^{\circ}$ 2080/92 marcou definitivamente a industrialização da floresta, atribuindo-lhe um elevado valor económico e definindo-a como o motor para a "utilização alternativa das terras agrícolas" e para o "desenvolvimento de atividades florestais nas explorações agrícolas". A propósito deste período de crescimento do pinheiro-bravo e posteriormente do eucalipto, Orlando Ribeiro (1986: 103) afirmou que "(...) Carvalhais, Soutos, e Pinheiros-Mansos, derrotados por milénios de cultura, nunca mais se reconstituíram. Só o pinhal e o eucaliptal vão ganhando terreno, subindo nas vertentes cobertas de mato, envolvendo o âmbito cultivado das povoações em grupos pequenos ou em bosques densos, monótonos, intermináveis".

Parte das mudanças verificadas devem-se também à forte incidência de incêndios florestais nas últimas dé- cadas, embora, estes sejam quase tão antigos como a ocupação humana, havendo registos de carvões fossilizados do Neolítico, como refere NunEs (2004: 27) o que traduz, a conquista de novos espaços para pasto desses povos, essencialmente pastoris, à custa do fogo. De resto, a paisagem característica do noroeste português, resulta da milenar ação modeladora das práticas concomitantes das atividades agrícolas e silvo-pastoris, bem adaptadas às características climáticas e aos condicionalismos morfológicos, edáficos e da rede hidrográfica.

Contudo, os espaços rurais atuais são espaços multiformes e diversificados, que não se resumem apenas à atividade agrícola e florestal, e que nas últimas décadas têm apresentado um conjunto de dinâmicas de mudança.

Os fenómenos de despovoamento de vastas regiões predominantemente agrícolas conduziram a alterações significativas na paisagem e levaram ao desenvolvimento de condições favoráveis à deflagração e propagação do fogo. Assim, as áreas anteriormente cultivadas deram lugar ao mato, ficando apenas como vestígio desse passado agrícola os socalcos.

Para FerRão (2000), o mundo rural estruturava-se numa tetralogia assente na função vocacional de produção de alimentos, em que a agricultura se assumia como a principal atividade económica, desenvolvida por grupos familiares, sendo esta a base da sociedade rural e que explorava os recursos da região imprimindo, assim, um cunho próprio na paisagem. Dicotomicamente afastado, o mundo urbano, distinguia-se nas funções, nas atividades económicas e nos modos de vida, contudo, mundo rural e urbano, eram interdependentes entre si.

$\mathrm{O}$ advento da Era Industrial trouxe consigo o fim do mundo rural secular "arcaico" e o florescimento das novas sociedades urbano-industriais, símbolos de desenvolvimento e progresso. O crescimento das áreas urbanas e industriais atribuiu uma nova função às áreas rurais, além do abastecimento alimentar dos mercados e de refúgio em momentos de crise às populações urbanas, a do fornecimento de mão-de-obra disponível, desqualificada e barata que acorre para a cidade atraída pela diversidade de serviços, funções e oportunidades.

As inovações tecnológicas introduzidas na agricultura no boom industrial do pós II Guerra Mundial, permitiram às áreas rurais alcançarem outro patamar de modernidade, não exclusiva das áreas urbanas, distinguindo-se assim o mundo rural moderno e o mundo rural tradicional.

Agora, a modernidade não é exclusiva do mundo urbano ou industrial, mas extensível ao mundo rural, 
apesar do peso indissociável de atraso deste último. Muito embora a prosperidade e dinamismo conheçam algumas regiões rurais, sobretudo as que encetaram processos de modernização agrícola, ganhando importância, opondo-se àquelas que estagnaram, votando-as a processos de perda demográfica e económica. Neste novo contexto, "a relação rural-urbano" bifurca-se, dando origem a uma partição das áreas rurais em função da sua proximidade (física mas também funcional e socioeconómica) aos principais centros urbanos. A diferenciação entre áreas rurais "centrais", "periféricas" e "marginais" ou ainda a designação de "áreas rurais profundas" evidenciam, com clareza, esta nova situação" (FerRão, 2000: 3).

Em virtude do seu dinamismo, as áreas rurais "centrais" e "periféricas" assumem relações de complementaridade com os centros urbanos. Inversamente as áreas rurais "marginais" ou "profundas", em resultado da sua crescente perda demográfica e económica vão gradualmente distanciar-se da sua relação com os centros urbanos, acentuando o desinteresse por estas mesmas áreas, muitas vezes agravada pelas fracas acessibilidades ao exterior.

Contudo, o progressivo abandono do espaço rural, que tem ocorrido essencialmente desde a década de (19)60, introduziu grandes mudanças. Segundo PerelRA (1988), citado por CUNHA (2007), as transformações mais significativas são o gradual processo de despovoamento, resultando num gradual envelhecimento da população, e em simultâneo, causa e consequência de transformações e destruição da economia agro-silvopastoril, associada às práticas comunitárias de uso e posse da terra.

Concomitantemente, ocorre a vontade da preservação do património rural não agrícola, no qual FERRÃo (2000) distingue três tendências: a renaturalização, promovendo a proteção dos espaços naturais; a procura de autenticidade, sobressaindo o património natural e arquitectónico (classificado e vernáculo) e as tradições culturais; e a mercantilização das paisagens, associada ao lazer.

Esta realidade evidencia a multi-atividade e multi-rendimento dos rurais, que assumem importância como agentes de preservação da paisagem rural nos aspectos económicos, sociais e ambientais. Estes espaços rurais não agrícolas caracterizados pelo seu reduzido dinamismo demográfico, social e onde o tecido económico e empresarial, introduzem o conceito de espaços de baixa densidade. Não obstante, assumem-se como lugares de eleição para o urbanita com elevada escolarização, pelo facto de preservar a identidade do lugar, remetendo-o para o elemento da tetralogia, a paisagem. A tendência de procura urbana destes espaços pode deixar antever que as dinâmicas futuras nos espaços rurais passarão por aí e já não associadas apenas à produção agrícola. No entanto, este refluxo por parte dos citadinos que rumam ao campo, pode constituir segundo LOURENço (1991), com a sua negligência, uma das causas dos incêndios florestais.

\subsection{A interface urbano-florestal}

As áreas caracterizadas pela coexistência entre vegetação, infra-estruturas e a respectiva ocupação humana, recebem a designação de interface urbano-florestal (IUF), que alguns autores designam de interface urbano-rural (IUR), que tem a sua tradução da bibliografia anglo-saxónica, wildland-urban interface (WUI).

Os territórios associados aos incêndios florestais na IUF apresentam uma contínua mutação, fruto de uma realidade complexa, entre diferenças nos revestimentos e coberturas das habitações, tipos de vegetação, dimensão dos lotes, tipo de ocupação, comportamento do proprietário, capacidade de extinção, legislação e aplicação da lei, níveis de seguros, entre outros, e consequentemente com diferentes danos ecológicos, económicos e humanos.

Apesar deste ser um problema que já acontecia desde os finais do século XIX nos E.U.A., foi após os grandes incêndios florestais que ocorreram neste país em 1985 que surgiu o interesse e desenvolvimento de estudos sobre incêndios na IUF pela iniciativa da National and State Interagency Wildland-Urban Interface Program. Os países europeus da bacia mediterrânea iniciaram os seus estudos posteriormente, debruçando-se sobretudo na vulnerabilidade partindo da análise espacial das características da vegetação e das habitações relativamente ao comportamento do fogo.

Os estudos realizados neste âmbito como o $\mathrm{Fi}$ reWise Action Program nos EUA, o Bushfire CRC Program na Austrália ou como refere VIEGAS ( 2011: 195) em Portugal apontam, de uma forma genérica, os mesmos factores de base para que ocorra a ignição de infraes truturas localizadas em áreas de IUF, nomeadamente : 1) a (in)existência de uma zona de proteção; 2) tipo e estado de conservação das edificações; 3 ) a origem da ignição a partir da vegetação circundante; 4) fatores naturais: topografia e vento.

As áreas de IUF podem dever-se a duas situações (Figura 2), a primeira prende-se com o crescimento das cidades para as suas periferias, com o aumento da pressão das áreas urbanas sobre as florestais, em consequência da expansão de áreas residenciais e/ou indus- 
triais, ampliando o perímetro urbano em torno de manchas florestais. Além disto, tem-se constatado um crescente aumento da procura pelas áreas rurais e florestais como espaço de lazer, com a compra de vivendas para primeira residência ou ócio em locais relativamente isolados rodeados por floresta. Na Europa, esta realidade ocorre sobretudo em França, na costa mediterrânea (CABAllero 2000, 2005; Lampin, 2006; TAVAREs e Cunha, 2009 e Vieira, 2009), por vezes com acessos estreitos e sem saída, o que, em presença de um incêndio, vai conduzir a uma dispersão de meios de combate, além de agravar o tempo de que os meios de socorro necessitam para chegar aos diferentes locais.

A segunda situação, que revela grande vulnerabilidade das áreas de interface, poderá dever-se aos processos de despovoamento e abandono funcional das áreas rurais, sobretudo no caso português, nas regiões rurais de montanha do interior, com o avanço da área florestal sobre o que até aí seriam campos de cultivo e, inclusive, infra-estruturas.

Em Portugal, nas regiões demograficamente deprimidas, onde o declínio da agricultura é uma realidade, habitações e edifícios de apoio à atividade agrícola têm vindo a ser abandonados, bem como os campos agrícolas contíguos, e com eles uma série de práticas agrícolas e silvo-pastoris que controlavam o volume de materiais lenhosos potencialmente combustíveis dando assim, lugar à expansão do mato e floresta (LoURENço, 1991, 2006 e 2008). Deste modo, essas infra-estruturas facilmente ficam cercadas por vegetação, colocando-as em situação de perigo perante um incêndio florestal, resultando geralmente na sua carbonização.

Ainda é de referir a pressão das áreas agrícolas sobre as florestais, com a realização de queimadas de resíduos agrícolas ou a renovação das pastagens, que poderão resultar em incêndios florestais. Estes nem sempre são resultado direto destas atividades, mas fruto da irresponsabilidade e incúria de quem as pratica, como a mal extinção de cigarros, ou faíscas libertadas por máquinas durante trabalhos na floresta.

Estes incêndios estão, por vezes, também associados a condições que favorecem a rápida propagação das chamas, tais como as condições dos combustíveis, meteorologia e topografia, desencadeando um comportamento violento do incêndio extremo do fogo, dificultando brigando com as operações de combate.

Esta situação, numa zona de interface urbano florestal, torna difícil o combate aos incêndios, tanto a nível de segurança como pela multiplicidade de solicitações aos meios de combate, especialmente quando, em simultâneo, ocorrem situações que põem em perigo vidas humanas, bens imóveis e áreas florestais, daí a necessidade de uma clara definição de prioridades e de uma eficaz gestão dos meios. Por vezes, na ausência de uma destas, pode não ficar assegurada a proteção a habitações e estruturas, que chegam mesmo a ficar destruídas, revelando assim fragilidades dos sistemas de combate que nem sempre estão preparados para ocorrências múltiplas, em simultâneo.

As áreas de IUF apresentam problemas típicos da gestão urbana, simultaneamente com os da gestão de terrenos florestais. Isto parece um conjunto específico de problemas, sob a forma de sinergia e interação entre as duas utilizações do solo. Um dos principais problemas encontrados em áreas IUF é o aparecimento de incêndios florestais. As pessoas que habitam as zonas urbanas e residenciais, entre manchas de florestas, dificilmente percebem o potencial de destruição dos incêndios florestais, sem que antes tenham sofrido os seus efeitos.

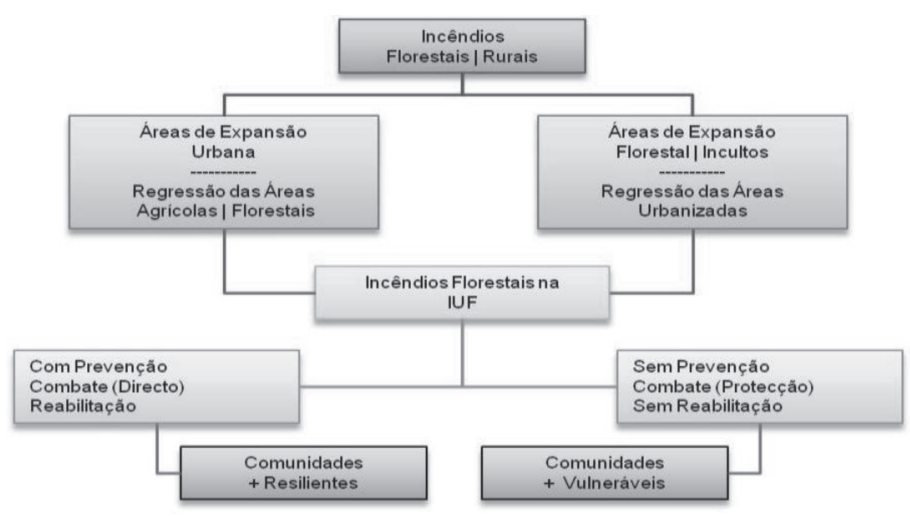

Figura 2

Esquema das situações de incêndio florestal na IUF em Portugal.

Fonte: Elaboração própria. 
As áreas de interface urbano-florestal carecem de uma abordagem onde os vários intervenientes possam coexistir com os seus diferentes interesses, evitando-se tensões e conflitos, mas, para tal, é necessário dotar de informação os cidadãos e todos os que percorrem estas áreas, para que possam decidir e agir em conformidade.

\section{Baião, território em mudança}

A realidade dos incêndios florestais em Baião não é um fenómeno recente, o mesmo não se poderá afirmar relativamente a incêndios na interface urbano-florestal. Porém, o adensar de ocorrências, como as verificadas no Verão de 2009, veio realçar a vulnerabilidade de alguns lugares, bem como o desconhecimento e a inoperância dos residentes nestas áreas perante os incêndios florestais na IUF, o que dificultou de sobremaneira a atuação dos meios de combate.

Este cenário é o resultado de condicionalismos de ordem humana e biofísica, que conduzem ao aumento da área de campos agrícolas incultos e consequentemente à expansão de matos (combustíveis finos) de elevada inflamabilidade até próximo de edificações, tais como residências, armazéns e indústrias, ou de novos assentamentos, urbanizações, habitações isoladas e fabriquetas, o que em grande medida amplia o risco na IUF.
Se, demograficamente a Região Norte apresentou nas últimas década um crescimento positivo, superior à média nacional, a tendência registada em Baião reflete uma perda acentuada de população, o que levou este território, apesar de integrado no distrito do Porto, a afirmar-se como espaço marginal de montanha.

Em 1960, Baião contava com 28864 habitantes, os Censos 2011 apontam para uma população residente de apenas 20522 habitantes. Estes quantitativos refletem uma tendência de decréscimo populacional trans versal às áreas rurais periféricas, fruto por um lado da emigração e por outro de um saldo negativo do crescimento natural (Figura 3).

Em 50 anos, Baião perdeu cerca de $29 \%$ da sua população. Esta foi uma perda generalizada, com a exceção de Campelo, a freguesia sede de concelho, que contraria esta tendência ao registar um aumento populacional de 39,4\%, absorvendo parte da população residente noutras freguesias. Baião, é pois, pautado por um forte decréscimo populacional que se justifica com a emigração no passado, principalmente para o Brasil, França e Luxemburgo e mais recentemente para Espanha e Angola, mas também pelo êxodo rural para a Área Metropolitana do Porto.

De acordo com Hespanha (1994), o êxodo rural e o despovoamento crescente do interior do país vieram mostrar que as atividades tradicionais, ligadas à explo-
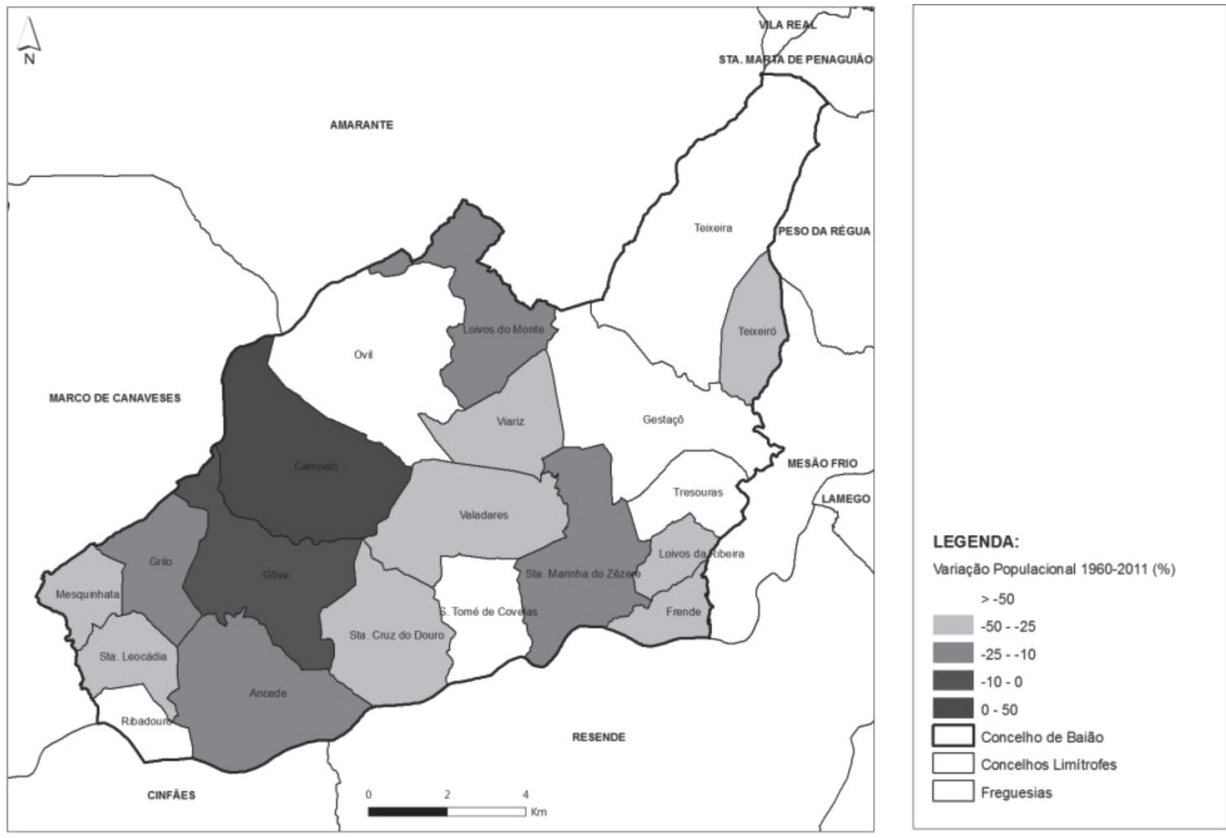

Figura 3

Variação populacional do concelho de Baião, por freguesia, entre 1960 e 2011.

Fonte: Recenseamento Geral da População, INE. Elaboração própria. 
ração da terra, não conseguem mais assegurar às populações das aldeias as condições mínimas para um padrão de vida decente e por isso se tornaram incapazes de reter essa população.

Ao longo deste período (1960-2001) verifica-se uma profunda alteração funcional. A partir da análise dos Censos de 1960, foi possível apurar que cerca de $67,5 \%$ da população do concelho estava afecta ao sector primário. Em 1981, esse valor baixa para 45\%, contudo nas freguesias de Teixeira, Teixeiró, Mesquinhata, Ovil, e S. Tomé de Covelas ainda persistiam percentagens superiores a $60 \%$. Em 1991 , apenas $22 \%$ da população estava afecta a este sector e em 2001 a percentagem fixase nos $8 \%$. Apesar deste decréscimo acentuado, a prática agrícola e pecuária em regime extensivo ainda subsiste, mas em sistema de pluriatividade. Desta forma, a paisagem continua a refletir estas atividades, que funcionam também como complemento ao orçamento familiar. No entanto, não deixam de se observar as tendências que ao longo das últimas décadas têm ocorrido em Portugal, nomeadamente após o 25 de Abril de 1974 e a adesão à CEE em 1986.

De facto, registou-se uma transferência de população do sector primário para o sector secundário e terciário, sendo que em 2001 mais de metade da população ativa já se encontrava afecta ao sector secundário (Figura 4). O sector terciário ainda é algo incipiente no concelho e em 2001, empregava apenas 37,7\%, enquanto a média nacional se cifrava em 59,9\%. Campelo, Ribadouro e Frende são as freguesias que registam uma maior percentagem de população afecta a este sector, respectivamente $57 \%$, $60 \%$ e $54 \%$. Poderemos explicar estes valores com o facto de Campelo ser a freguesia sede de concelho, onde existe um maior número de ser- viços. No caso das freguesias de Ribadouro e Frende esses valores resultam do elevado número de pessoas que trabalham nas empresas CP e REFER, bem como as que se deslocam diariamente por caminho-de-ferro para o Grande Porto.

O sector secundário afirmou-se ao longo destas três décadas como o grande empregador do concelho, sobretudo no sector da construção. Se em 1981 não existia nenhuma freguesia com percentagens superiores a 50\% de população afecta a este sector, em 1991 já eram nove e em 2001, quinze, destacando-se Viariz com 78,5\% e Gôve com 68,6\%.

A qualificação académica da população também contribui para justificar a distribuição percentual da população ativa por sector de atividade. Apesar de substancialmente inferiores à percentagem nacional de 7,16\%, é nas freguesias de Campelo, Ribadouro e Frende que se registam os valores mais elevados de população com qualificação acima do Ensino Secundário. É também nestas freguesias que se verificam as maiores percentagens de população afecta ao sector terciário, como vimos anteriormente. Por oposição, as freguesias de Loivos do Monte, Teixeira e Teixeiró apresentam valores acima de $30 \%$ de população que não sabe ler nem escrever e acima de $40 \%$ que apenas possui o $1^{\circ} \mathrm{Ciclo}$ do Ensino Básico.

\subsection{As novas IUF}

É neste quadro geográfico e social de um território marginal de montanha, de baixa densidade demográfica e funcional, com baixas qualificações, envelhecido, onde os processos de despovoamento contribuem para alterações na paisagem que os incêndios florestais se manifestam. Com efeito, as alterações na ocupação e uso do solo

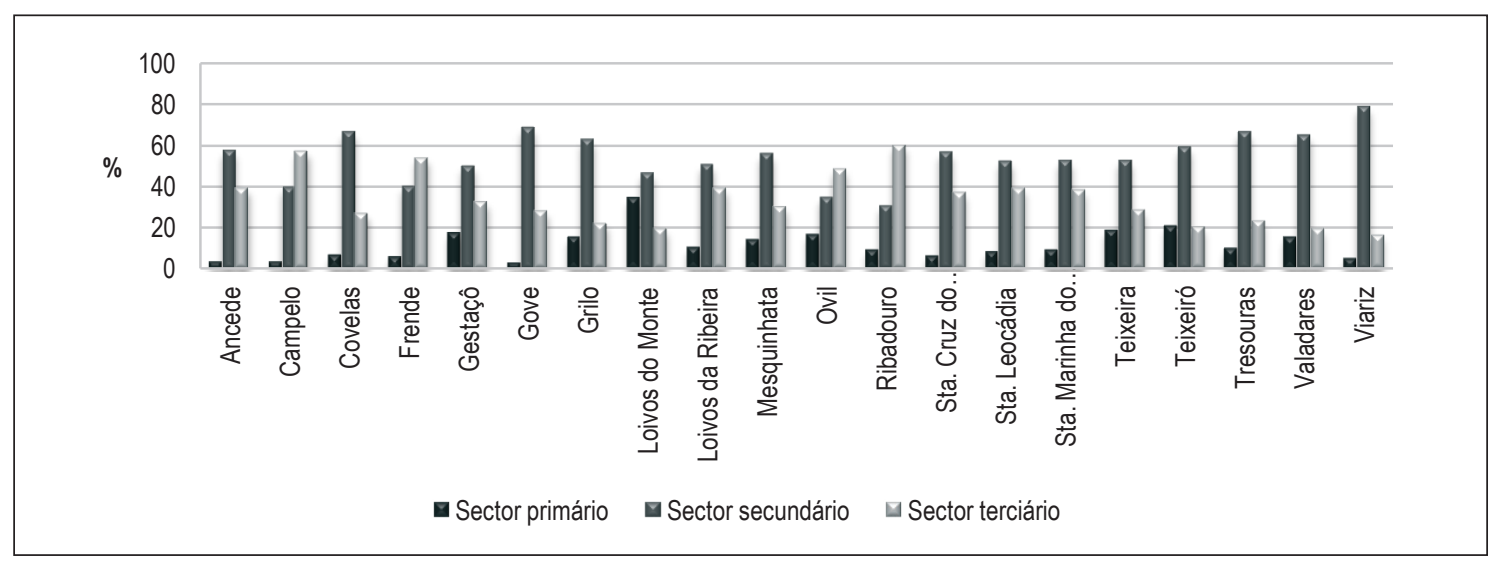

Figura 4

População ativa por sectores de atividade, em 2001.

Fonte: Recenseamento Geral da População, INE. Elaboração própria. 
observadas, revelam uma diminuição das áreas agrícolas, consequência do seu abandono, e o aumento das áreas florestais, o que dá origem as novas áreas de IUF que pelas suas características expõem, na maioria das vezes, esta população pouco resiliente e vulnerável, à plena manifestação do risco de incêndio florestal.

Note-se, que cerca de $8 \%$ da área do concelho de Baião pode classificar-se como área de interface urbano-florestal, resultante do contacto entre áreas classificadas como "tecido urbano" e outras classificadas como "floresta" ou "matos ou incultos" numa faixa de 100 metros a partir do limite do "tecido urbano". Mas se se atender ao facto do povoamento ser essencialmente disperso, em que as habitações estão muitas vezes distantes entre si várias dezenas de metros ou até centenas, como sucede com pequenos lugares e habitações isoladas e que por isso não se considera "tecido urbano", percebe-se que as áreas de IUF são mais extensas rondando 20\% do território municipal (Figura 5).

Entende-se que as áreas de interface urbano-florestal não são uma linha entre o solo urbano e a vegetação, mas sim uma área heterogénea onde as estruturas e a vegetação se misturam criando uma faixa. Deste modo, a distância até 100 metros a partir do "tecido urbano" é até onde as características de IUF são mais evidentes, e a partir daí caracterizando-se simplesmente como floresta, matos ou incultos.
As áreas de IUF resultantes da expansão urbana caracterizam-se por serem ocupadas por pessoas mais jovens, com um nível académico secundário ou superior. As habitações têm na generalidade logradouros e acessos mais facilitados, em asfalto ou empedrado e apesar de grande parte delas não possuir um sistema de combate a incêndios, existem torneiras nos jardins e quintais com a finalidade primária de regar, mas com a finalidade secundária e intencional de proteção da habitação em caso de incêndio florestal. Por conseguinte, os meios de socorro podem focalizar a sua atuação no combate direto dos incêndios florestais, uma vez que os proprietários das habitações realizam a proteção das estruturas. O nível de (in) formação e a sua capacidade financeira permite reabilitar os possíveis danos, revelador da sua maior resiliência.

Não obstante, a reduzida resiliência que genericamente caracteriza estas comunidades deve-se ao facto de parte significativa da população ter baixo nível de escolaridade, e por outro apresentar um envelhecimento crescente, constituindo-se como uma barreira à transmissão de informação, à sensibilização, à educação para uma cidadania ativa e pró-ativa.

\subsection{Análise prospectiva da IUF e propostas de ação}

Com o intuito de atribuir coerência ao planeamento territorial e à gestão da emergência, nomeada-

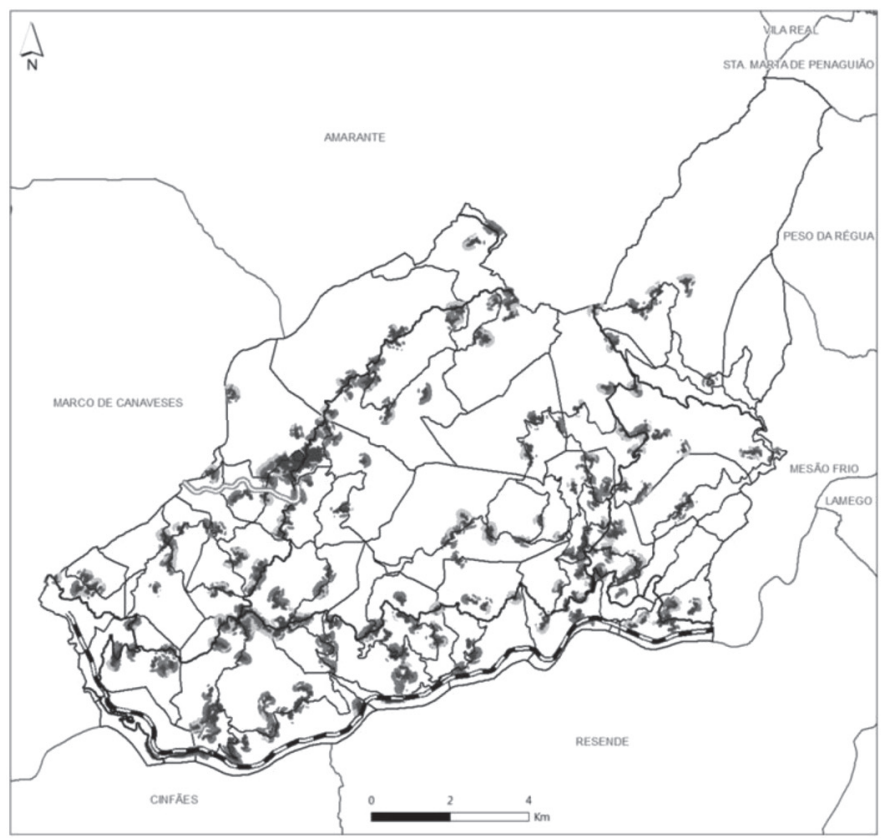

LEGENDA:

Rede Viária

Itinerário Complementa

- Estrada Nacional

- Estrada Municipal

Rede Ferroviária

- Caminho-de-Ferro

Uso do Solo

Indüstria e comércio

Tecido Urbano

Floresta

Fll- Florestas abertas

5 Freguesias

5 Concelhos Limitrofes

Figura 5

Área de Interface Urbano-Florestal no concelho de Baião.

Fonte: Elaboração própria. 
mente nos incêndios florestais, torna-se necessário o cumprimento do Decreto-Lei n. ${ }^{\circ} 327 / 90$, de 22 de Outubro, com as alterações introduzidas pelos diplomas subsequentes (Lei n. ${ }^{\circ} 54 / 91$, de 8 de Agosto; Dec.-Lei n. ${ }^{\circ}$ 34/99, de 5 de Fevereiro; Dec.-Lei 55/2007, de 12 de Março e Declaração de Rectificação n. ${ }^{\circ} 37 / 2007$, de 9 de Maio) que estabelece a proibição de construção em áreas não classificadas nos PMOT como solos urbanos, urbanizáveis ou industriais no prazo de 10 anos subsequentes a um incêndio.

O não cumprimento sistemático do Decreto-Lei 124/2006, de 28 de Junho, ratificado pelo Decreto-Lei 17/2009, de 14 de Janeiro, que define as distâncias mínimas limpas de vegetação entre as estruturas relativamente à floresta, pode antever consequências graves em estruturas e povoações na presença de um incêndio florestal.

Se grande parte das habitações integrantes da classificação "solo rural" não cumpre estes dispostos legais, as localizadas em "solo urbano", que se distribuem essencialmente ao longo dos principais eixos viários do concelho, caiem num vazio legal, por não se ter efectuado a transposição destes regulamentos para as referidas áreas. Esta lacuna legal deixa as habitações e outras estruturas em áreas de IUF, mas que integram o "solo urbano", sem qualquer medida no que se refere aos incêndios florestais e à sua prevenção. É pois necessário ultrapassar esta lacuna, que poderá passar pela elaboração de um regulamento municipal que defina as regras de segurança contra incêndios florestais em áreas classificadas como urbanas, isto, enquanto a lei geral não abranger também as áreas urbanas e elaborar legislação específica para as áreas de interface urbano-florestal.

Perante isto é preocupante a vulnerabilidade destas habitações, agravada pelo desconhecimento generalizado dos seus proprietários sobre o perigo dos incêndios florestais, que poderão ter consequências imprevisíveis.

O pressuposto de prevenção do risco associado aos incêndios florestais em áreas de IUF deverá conduzir os serviços de Proteção Civil locais a identificarem e analisarem as áreas de interface, desenvolvendo iniciativas de sensibilização e de maior proximidade com as populações, sendo esta a plataforma inicial de trabatho, que permitirá caracterizar esta problemática e elencar medidas de intervenção de prevenção e mitigação. A análise da IUF deverá contemplar três escalas: do concelho; da freguesia/lugar e da infraestrutura.

O primeiro nível de análise permitirá identificar as freguesias prioritárias e onde o fenómeno assume maior expressão, com a identificação das áreas de IUF resultantes da expansão das áreas urbanas e da expansão das florestas e matos.

Para a abordagem à escala da freguesia ou lugar, será útil a identificação de pontos sensíveis e consequentemente a elaboração de planos de emergência locais. Estes planos de emergência deverão contemplar informação atualizada sobre o tipo de estruturas, as suas características, o seu número e tipo de uso. Será importante caracterizar as vias de acesso, o que permitirá aos gestores de emergência planear a estratégia a adoptar em cada circunstância, optando pelo confinamento ou evacuação das localidades, durante a ocorrência de um incêndio florestal. O elemento humano também deverá ser tido em consideração, com a identificação de residências de idosos com mobilidade reduzida e de instalações sensíveis, como centros de dia e lares de $3^{\mathrm{a}}$ idade, estabelecimentos de ensino, unidades hoteleiras, uma vez que os seus ocupantes desconhecem os lugares seguros e pontos de encontro que se venham a definir, sendo, por isso, prioritários em situação de emergência.

Esta tarefa deverá requerer a cooperação das diversas entidades de proteção civil, tendo as juntas de freguesia um papel relevante, por quanto a sua proximidade com as populações e o conhecimento da sua realidade social e económica, certamente, permitirão tomar medidas mais eficazes.

O último nível de intervenção, a uma grande escala, deverá contar com o contributo dos serviços municipais de obras particulares, aquando do licenciamento de novas construções. A sua implementação passaria pela identificação da localização pretendida por cada projeto de obra, pelo que, deste modo, seria possível saber se esse projeto estaria numa área classificada como IUF ou iria criar uma nova área de IUF e desse modo requerer o cumprimento de normas e regulamentos específicos de proteção contra incêndios desta natureza. Desta forma seria possível trabalhar numa perspectiva preventiva e simultaneamente reativa, uma vez que em caso de incêndio estas estruturas (habitações, indústrias, armazéns,...) estariam preparadas com mecanismos de autoproteção.

É pois necessária a cooperação entre as entidades e organismos referidos, que poderia materializar-se com o reforço das ações de sensibilização nas escolas e especialmente com os Clubes de Proteção Civil escolares. Com os mais idosos, e uma vez que, aproximadamente, $16 \%$ da população do concelho tem mais de 65 anos, a realização de ações de sensibilização em centros de dia e nas paróquias seria viável. Ainda assim, apesar da maior mobilidade e capacidade de ação, a 
população adulta manifesta desconhecimento sobre procedimentos básicos de prevenção e reação aos incêndios florestais na IUF. Os órgãos de comunicação social locais deveriam passar a ter um papel ativo na tarefa de sensibilizar a população sobre medidas de autoproteção, contribuindo assim para a sua formação e não serem apenas um veículo de informação.

Em torno das habitações e outras estruturas a sistemática acumulação de vegetação, por vezes lixo ou até monos, como automóveis abandonados ou electrodomésticos, e ainda a existência de palheiros e de provisões de lenha guardada em lugares sem qualquer limpeza da vegetação envolvente, cria sérias dificuldades aos bombeiros durante a sua proteção contra incêndios.

A falta de sensibilização e de um civismo preventivo é outro aspecto que dificulta as operações em curso nos Teatros de Operações, sobretudo os cidadãos que não estando a ajudar os meios de socorro ou a proteger os seus bens, mas que se deslocam a pé, de carro ou de mota para observar o incêndio, obstruindo as ruas. Apesar de frequente, seria vantajoso para os meios de socorro e para a segurança da população, o condicionamento de circulação nos teatros de operações. Esta medida também se deveria aplicar aos órgãos de comunicação social, que para mostrarem e relatarem a "tragédia" se colocam em situações de perigo desnecessárias, acrescentando preocupações aos bombeiros e por vezes dificultando os trabalhos em curso.

Por outro lado, seria oportuno que a Autoridade Nacional de Proteção Civil criasse a tipologia de "incên- dio florestal na interface urbano-florestal", pois permitiria atribuir prioridade às intervenções na IUF e, consequentemente, o envio de meios para o combate direto, outros para a proteção de exposições e ainda para realizar confinamentos e/ou evacuações. Mas, primeiro, é necessário atualizar os procedimentos dos bombeiros, com métodos adequados a estes cenários, possibilitando que as equipas envolvidas estejam com uma missão específica no TO. Assim, teríamos uma maior organização nos TO, com operações mais seguras para as populações e para os meios de socorro e os incêndios nunca deixariam de ser combatidos, em virtude de outras prioridades, o que iria dificultar o seu desenvolvimento pois não se verificaria essa falta de combate.

Atualmente, qualquer incêndio que deflagre em floresta, incultos, matos ou na IUF tem o mesmo grau de prioridade, ou seja, são todos englobados numa mesma tipologia, não fazendo distinção de situações potencialmente mais perigosas que outras, nomeadamente habitações em risco.

Contudo, podem-se adoptar novas atitudes e comportamentos, promovendo o envolvimento entre as comunidades, os agentes de proteção civil e os ór gãos de gestão territorial num compromisso integrado (Figura 6).

O Plano Nacional de Defesa da Floresta Contra Incêndios (PNDFCl), no seu Eixo 3, prevê aumentar a resiliência do território aos incêndios florestais. Para isso, define um conjunto de medidas que passam pela criação e manutenção de faixas exteriores de proteção,

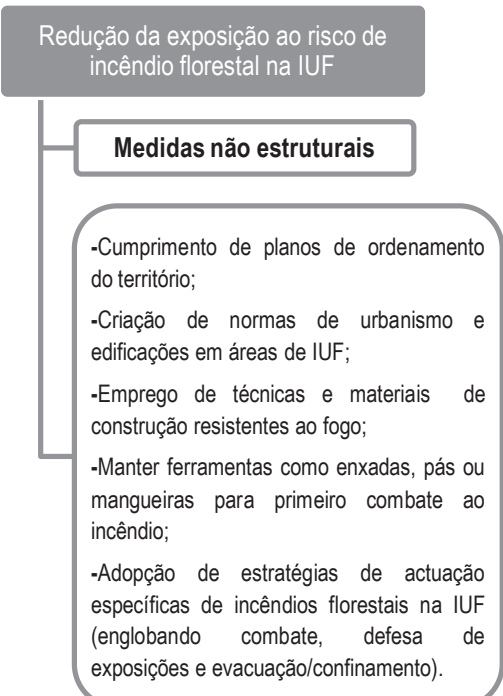

Redução da exposição ao risco de incêndio florestal na IUF

Medidas não estruturais

-Cumprimento de planos de ordenamento do território;

-Criação de normas de urbanismo edificações em áreas de IUF construção resistentes ao fogo;

-Manter ferramentas como enxadas, pás ou mangueiras para primeiro combate ao incêndio;

específicas de incêndios florestais na IUF exposições e evacuação/confinamento).

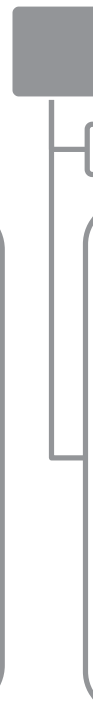

Domínio físico da IUF

Medidas estruturais

- Criação de faixas de contenção em torno de povoações (campos de cultivo e pastagens);

-Criação de barreiras corta-fogo em volta das habitações;

-Programas de reflorestação e sivicultura preventiva;

-Ordenamento florestal evitando a monocultura de espécies de elevada combustibilidade;

-Prescrição de fogo controlado.
Redução dos impactes dos incêndios florestais na IUF

Medidas não estruturais

-Educação cívica da população para a problemática dos incêndios florestais na IUF

-Promoção da prevenção e resiliência das populações;

-Planos de emergência específicos de actuação na IUF;

-Programas de seguros:

-Reconstrução e reabilitação de áreas de IUF ardidas. 
nos aglomerados populacionais, intervindo prioritariamente nas zonas com maior vulnerabilidade aos incêndios; criação e manutenção de faixas exteriores de proteção em aglomerados populacionais, em parques industriais, aterros sanitários, habitações, estaleiros, armazéns, oficinas e outras edificações, e, por fim, a fiscalização dessas mesmas faixas. Segundo TAVAREs e CunHa (2009: 2), este plano "realça a criação de um modelo territorial coerente comportando um sistema de prevenção e gestão dos riscos, assim como considera nos objectivos estratégicos de desenvolvimento do país, a avaliação e prevenção de factores e de situações de risco com vista ao desenvolvimento de medidas de minimização dos respectivos efeitos", devendo estas medidas serem transcritas para os Planos Municipais de Defesa da Floresta Contra Incêndios.

Ainda que a interface urbano-florestal apresente genericamente os mesmos elementos expostos aos incêndios florestais em qualquer parte do mundo ou do território nacional onde ocorra, a abordagem do combate a este problema é feita de forma distinta no território nacional. Veja-se o exemplo dos incêndios na IUF ocorridos em Pernigem, em 2008, ou em Belas, em 2009. Neste último arderam cerca de 20 ha de mato, mobilizando cerca de quatrocentos bombeiros, apoiados por meios aéreos. Em Eiriz - Baião, em 2009, a área ardida foi cerca de vinte vezes superior e o dispositivo de combate cinco vezes inferior, com várias centenas de pessoas afetadas direta ou indiretamente pelo incêndio em quatro freguesias, com a diferença de que não vivem num condomínio de luxo.

Será portanto necessário intervir nestes cenários de forma eficaz, célere e sem receio do peso social dos afectados pelos incêndios na IUF e da maior ou menor presença da comunicação social. Deste modo, a presença de rádios, jornais e televisões nos cenários de plena manifestação de crise, deverá ser regulamentada, para se evitar o "vale tudo" para a obtenção da notícia, que muitas vezes deixa de ser o acidente em si mesmo, mas acontecimentos secundários, levando a situações de desinformação.

A vigilância das matas e florestas é um meio de detecção precoce que permite antecipar e prever a progressão dos incêndios em direção a localidades e infraestruturas, possibilitando a evacuação de localidades e habitações atempadamente. Desta forma, a implementação de sistemas de vigilância electrónica permitirão a monitorização de vastas áreas do território, controladas a partir de uma central, com vantagens ao nível da observação noturna com recursos a câmaras térmicas e infravermelhos, a que se associa o baixo cus- to de operação, uma vez que não requer a presença de pessoas e veículos em vigilância no terreno, bem como a possibilidade de monitorização de determinadas áreas com grande rapidez, evitando a deslocação de meios móveis de vigilância, são vantagens que justificam a implantação de sistemas deste tipo em áreas particularmente sensíveis.

\section{Conclusão}

Não havendo uma cultura do risco, nem tão pouco qualquer tipo de preparação e sensibilização das populações por parte dos organismos competentes, não será fácil inverter a tendência que se adivinha no agudizar de situações de incêndios na interface urbanoflorestal.

Verifica-se assim que as áreas de IUF têm aumentado, principal consequência da expansão das áreas urbanas e do surgimento de novas edificações, muitas delas desintegradas de qualquer plano de urbanização, isoladas em manchas florestais.

Em Baião, as áreas de IUF resultam, por um lado da expansão das áreas urbanas e por outro a expansão das áreas florestais. Mas, se por um lado a expansão das áreas urbanas e sobretudo a proliferação de habitações isoladas cria novas áreas de IUF, ampliando a sua exposição ao risco, por outro, verifica-se que as novas estruturas estão menos vulneráveis, em virtude da melhor qualidade de construção dos dias de hoje. O mesmo não se poderá afirmar relativamente à interface urbanoflorestal resultante da expansão das florestas. Aqui, na generalidade, encontram-se habitações e outras estruturas antigas, com materiais exteriores inflamáveis e com baixo nível de isolamento, agravado pela proximidade da vegetação, por vezes em contacto direto com o próprio edifício.

Verifica-se ainda que a expansão da floresta cria novas interfaces em áreas que anteriormente estiveram associadas à actividade agrícola. Estas áreas de IUF são caracterizadas pelo envelhecimento da população, relativamente a outros lugares dessas mesmas freguesias. Esta população reside em habitações antigas, por vezes contíguas de outras abandonadas e degradadas. Neste contexto, encontram-se lugares e aldeias que têm fracos acessos e em caso de emergência, o trânsito dos veículos de socorro é dificultado, atrasando o início das operações de combate o que vai obrigar os bombeiros a efetuarem essencialmente proteção de exposições. Assim, após o incêndio, estas comunidades não conseguem reabilitar o seu lugar ou os bens destruídos, es- 
tando dependentes da ajuda externa, geralmente de familiares.

Seria benéfico criar condições para um maior envolvimento das pessoas com a preservação do ambiente, e consequentemente com a prevenção dos incêndios em que se incluem os incêndios florestais na IUF. Assim, é fundamental o papel que as escolas, a Igreja, clubes, associações ambientais e juntas de freguesia podem ter na capacitação da população em agir perante um incêndio na IUF, ou noutros cenários de risco.

Se muitas vezes a manifestação do risco de incêndio florestal na IUF é inevitável, a recuperação das áreas ardidas deverá ser uma prioridade. Com uma política de ordenamento florestal, poderão corrigir-se factores condicionantes dos incêndios como as extensas áreas de monocultura de pinheiro ou eucalipto sem qualquer descontinuidade. Assim, mesmo que não se evite no futuro a sua ocorrência, pelo menos os seus impactes poderão ser minimizados.

\section{Bibliografia}

BLANCHI, R. et al. (2006) - Lessons learnt from post bushfire surveys at the urban interface in Australia. BCRC, Australia.

Caballero, D. (2000) - Gestión de los riesgos de incendios en la interfase forestal - urbana: Proyecto WARM. Disponivel: http://www.fs.fed.us/psw/publications/ (Fevereiro de 2011.

Caballero, D. et al. (2005) - Wildland-Urban Interface Management: A State of the Art. EUFIRELAB: EuroMediterranean Wildland Fire Laboratory, a "wall-less" Laboratory for Wildland Fire Sciences and Technologies in the Euro-Mediterranean Region.

Cohen, J. e Butler, B. (1998) - "Modeling Potential Structure Ignitions from Flame Radiation Exposure with Implications for Wildland/Urban Interface Fire Management". Proceedings of the 13th conference on fire and forest meteorology, vol. 1, October 27-31; Lorne, Victoria, Australia. Fairfield, WA: International Association of Wildland Fire; 81-86.

CoRTner, J. e LoRensen, T. (1997) - "Resources versus structures: Fire suppression priorities in the wildland/urban interface". Wildfire. 6(5):23-33.

CUNHA, L. (2007) - "Portugal mountain regions .Challenges for the 21st century". In: Jones, Garret; LeIMGRUBer, Walter e NeL, Etienne Issues in Geographical Marginality. IGU, Grahymstown. CDRom.

FERRÃo, J. (2000) - "Relações entre mundo rural e mundo urbano: evolução histórica, situação actual e pistas para o futuro". Sociologia, Problemáticas e Práticas, n³3, pp. 45-54.

Hespanha, P. (1994) - "Os Recursos Florestais no Desenvolvimento Rural - Alguns Aspectos Sociológicos de Enquadramento". Actas do III Congresso Florestal Nacional. Figueira da Foz.

LAMPIN, C. (2006) - "WUI and road networks/vegetation interfaces characterizing and mapping for forest fire risk assessment". V International Conference on Forest Fire Research.

LouREnçO, L. (1991) - "Aspectos sócio-económicos dos incêndios florestais em Portugal" in Separata de Biblos. FLUC: Coimbra.

Lourenço, L. (2006) - "Incêndios florestais: algumas reflexões e mitos do combate". Territorium, 13, pp. 59-70. Coimbra.

LOURENÇO, L. (2008) - "Urban-forest interfaces: a favourable stage for the incidence and development of forest fires in Portugal" Australasian Journal of disaster and trauma studies, vol. 2, 27 p. http://www.uc.pt/fluc/nicif/ Publicacoes/Estudos_de_Colaboradores/PDF / Publicacoes_periodicas/2008_australasian_journal_of_ disaster_and_trauma_studies.

Nunes, M. (coord) (2011) - Serra da Aboboreira, a Terra, o Homem e os Lobos. CMA, Amarante.

Palva, J. (2010) - A Biodiversidade e a História da Floresta Portuguesa. Comunicação apresentada no âmbito dos Dias da Ciência e da Tecnologia. Disponível: http:// www.esfafe.pt/citec/images/stories/sembiod/sintese_ jpaiva.pdf (Junho de 2011).

Ribeiro, O. (1986) - Portugal, o Mediterrâneo e o Atlântico: esboço de relações geográficas. Livraria Sá da Costa Editora. Lisboa.

RICE, C. e Davis, J. (1991) - Land-use planning may reduce fire damage in the urbanwildland intermix. United States Department of Agriculture. Forest Service. General Report. PSW-127.Pacific Southwest Research Station, Berkeley, California

Tavares, A. e Cunha, L. (2009) - "Riscos naturais e ordenamento do território espaços-risco e interfaces territoriais na região centro". Actas do VI Congresso da Geografia Portuguesa. Lisboa.

VÉLES, R. (coord.) (2009) - La defensa contra incendios forestales. McGrawHill.

VIEGAS, D. (coord.) (2011) - Incêndios Florestais. Verlag Dashöfer, Lisboa.

Vieira, A., Bento-Gonçalves, A., Lourenço, L., Martins, C. Oliveira e Ferreira-Leite, Flora (2009) - "Risco de incêndio florestal em áreas de interface urbano-rural: 0 exemplo do Ave." Territorium, Revista da Associação Portuguesa de Riscos, Prevenção e Segurança, Lousã, n 16 , p. 139-146 http://www.nicif.pt/riscos/Documentos/T_PDF/ T16artigos/T16art13 